\title{
Bilan au 31 décembre 2000
}

Exercice: 2000

Date: 30 avril 2001

Désignation

ACTIFS

Capital de roulement

Banques

Titres et valeurs

Total des liquidités et titres de valeurs

Créances sur prestations envers des tiers

Créances envers des organisations affiliées

Autres créances à court termes envers des organisations affiliées

Autres créances à court termes

Total des créances

Actifs de régularisation

Total du capital de roulement

Capital investi

Titres

Participations

Créances à long terme envers des entreprises affiliées

Total des investissements financiers

Biens mobiliers

Biens immobiliers

Total du capital investi

Total ACTIFS

PASSIFS

Capitaux confiés

Dettes à court terme

Dettes vis-à-vis de sociétés liées

Dettes financières spéciales à court terme

Passifs de régularisation

Total des capitaux confiés à court terme

Capitaux confiés à long terme

Charge financière à long terme

Provisions à long terme

Total des capitaux étrangers à long terme

Capital effectif

Capital

Gain de l'exploitation

Total du capital effectif

Total PASSIFS
2000

Fr.

473571.15

158263.20

631834.35

29012.35

33225.00

50000.00

5235.35

117472.70

1500.85

750807.90

1000.00

617200.00

1405000.00

2023200.00

31902.00

1214000.00

3269102.00

4019909.90

23202.00

85215.20

0.00

36500.00

144917.20

745000.00

83250.00

828250.00

3010715.48

36027.22

3046742.70

4019909.90
1999

Fr.
107634.66

158263.20

265897.86

35890.45

12970.50

95016.62

3436.30

147313.87

1215.25

414426.98

1000.00

617200.00

1620000.00

2238200.00

63802.00

1231800.00

3533802.00

3948228.98

36855.40

602.00

4706.10

20600.00

62763.50

745000.00

129750.00

874750.00

3008062.36

2653.12

3010715.48

3948228.98 


\section{Compte d'exploitation du $1^{\text {er }}$ janvier au 31 décembre 2000}

Exercice: 2000

Date: 30 avril 2001

Désignation

Produits d'exploitation

Fiduciaire

Cautionnements

Total des produits d'exploitation

Frais du personnel

Traitements et salaires

Charges sociales

Autres dépenses pour le personnel

Prestations de la part de tiers

Total des frais de personnel

Résultat brut 2

Autres frais d'exploitation

Frais de locaux

Frais de véhicules et de transport

Assurances choses, redevances, taxes

Frais d'énergie et taxes d'ordures

Frais de publicité

Autres frais d'exploitation

Résultat financier

Total des autres frais d'exploitation

Cash Drain

Amortissements

Biens financières

Biens mobiliers

Total des amortissements

Résultat d'exploitation 1

Résultat d'exploitations annexes

Recettes provenant de placement financiers

Résultat de l'immeuble

Revenues des loyers

Intérêts hypothécaires

Autres charges immobilières

Contributions, impôts

Assurances

Amortissements

Total des résultats de l'immeuble

Total du résultat d'exploitations annexes

Résultat d'exploitation 2

Résultat extraordinaire et hors exploitation, impôts

Résultat extraordinaire

Résultat d'exploitation avant impôts

Impôts

Gain d'exploitation
37631.75

2000

Fr.

1999

Fr.

\begin{tabular}{|c|c|}
\hline 0.00 & 3.10 \\
\hline 975.35 & 1556.05 \\
\hline 975.35 & 1559.15 \\
\hline-16562.50 & -30123.00 \\
\hline-2934.65 & -7830.45 \\
\hline-3565.75 & -7305.15 \\
\hline-4866.30 & -7425.40 \\
\hline-27929.20 & -52684.00 \\
\hline-26953.85 & -51124.85 \\
\hline-21674.60 & -68347.95 \\
\hline 6891.25 & 9353.75 \\
\hline-1000.00 & 0.00 \\
\hline-27850.00 & -46069.75 \\
\hline-51598.20 & -14014.25 \\
\hline 0.00 & -100.00 \\
\hline 74093.57 & 81205.32 \\
\hline-21137.98 & -37972.88 \\
\hline-48091.83 & -89097.73 \\
\hline 0.00 & -32300.00 \\
\hline-31900.00 & -28338.70 \\
\hline-31900.00 & -60638.70 \\
\hline-79991.83 & -149736.43 \\
\hline 13844.70 & 9207.15 \\
\hline 137610.00 & 150000.00 \\
\hline-29166.25 & -27942.65 \\
\hline 0.00 & -6789.35 \\
\hline-3415.35 & 0.00 \\
\hline-1703.30 & 0.00 \\
\hline-17800.00 & 0.00 \\
\hline 85525.10 & 115268.00 \\
\hline 99369.80 & 124475.15 \\
\hline 19377.97 & -25261.28 \\
\hline 37631.75 & 37991.20 \\
\hline 57009.72 & 12729.92 \\
\hline-20982.50 & -10076.80 \\
\hline 36027.22 & 2653.12 \\
\hline
\end{tabular}




\section{Annexe}

Exercice 2000

Date: 30 avril 2001

Désignation

1. Informations facultatives selon l'art. 663b CO

1.1 Cautionnements en faveur de tiers dont montant sollicité

1.2 Garantie d'actifs pour propres engagements

1.3 Valeurs d'assurance-incendie des immobilisations corporelles Biens mobiliers Biens immobiliers

Immeuble de la Elfenstrasse 18, Berne: Fr. 4400000.00 , dont copropriété FMH-Services: 50\%
Exercice

Fr.

1665000.00

1407500.00

1214000.00

3065850.00

865850.00

2200000.00
Année précédente

Fr.

2595000.00

2097125.00

1231800.00

3065850.00

865850.00

2200000.00

La police d'assurance concernant les biens mobiliers couvre également ceux de FMH Inkasso Services SA et de FMH Consulting Services SA; ceux-ci sont donc compris dans la valeur d'assurance-incendie. 